\title{
Investigation of Shell and Tube Heat Exchanger with Disc-and-Doughnut Baffles
}

\author{
Kuerbanjiang Wusiman*, Zhaolun Zhou \\ School of Electrical Engineering, Xinjiang University, Urumqi, China \\ Email: ^Jiang-dlut@163.com
}

How to cite this paper: Wusiman, $\mathrm{K}$. and Zhou, Z.L. (2020) Investigation of Shell and Tube Heat Exchanger with Disc-and-Doughnut Baffles. Open Access Library Journal, 7: e6762. https://doi.org/10.4236/oalib.1106762

Received: August 31, 2020

Accepted: September 7, 2020

Published: September 10, 2020

Copyright $\odot 2020$ by author(s) and Open Access Library Inc.

This work is licensed under the Creative Commons Attribution International License (CC BY 4.0).

http://creativecommons.org/licenses/by/4.0/

\section{(c) (i) Open Access}

\begin{abstract}
Disk and doughnut baffles configuration for shell tube heat exchangers (STHXs) is one of the solutions for compensating the higher pressure drop penalty induced by conventional segmental baffles. Furthermore, absently reliable references for the optimum design of this type of STHXs are our main purpose to carry out this investigation. From modeling numerical simulation results, with 7 baffles and $70 \%$ baffles ratio geometrical dimension is suggested the optimum configuration of this type of heat exchange. Additionally, the characteristic of heat transfer performance is discussed by varying the flow velocity in all different flow regimes of shell and tube side respectively through conducting the experimental apparatus. Hopefully this result could provide validating information in optimum design of STHXs with disk and doughnut baffles.
\end{abstract}

\section{Subject Areas}

Thermodynamics Engineering

\section{Keywords}

Shell Tube Heat Exchanger, Disc-and-Doughnut Baffles, Heat Transfer Coefficient

\section{Introduction}

Shell tube heat exchangers (STHXs) are quite widely applied in recent industry process, such as power plant, chemical engineering, petroleum refining, and food processing, etc. [1] [2]. Due to the merits of easy maintenance and possible upgrade for their robust construction, it is mentioned that more than $35 \%-40 \%$ of heat exchangers are of shell-and-tube types in the industry engineering process [3]. The most commonly utilized baffle in STHXs configuration is the segmental baffle. It exhibits that this typically utilized baffle of heat exchanger 
has been well-developed in prior research work [4] [5] [6]. The former research also validated that this conventional type of heat exchangers have higher heat transfer coefficient with a large pressure drop penalty [7] [8] [9] [10]. However, the dramatic zigzag flow pattern which is made by segmental baffles caused high risk of vibration failure on tube bounder [11] [12] [13].

To overcome the above mentioned drawbacks of conventional segmental baffles, one of the solutions is in regard to utilizing various types of baffles such as deflector baffles, disk-and-doughnut baffles configuration, spacing optimized baffles [14] [15] [16] [17]. Comparing with segmental baffles, some researches demonstrate that disk-and-doughnut baffles have higher effectiveness of hate transfer to pressure drop [4] [18]. Due to the radial flow formed between the bundle centre and periphery, it can eliminate bundle bypass, and make much lower cross-flow mass velocity than that of segmental baffles [19]. The disk and doughnut baffles type of STHXs have not been achieved as similar popularity as segmental baffle type, mainly due to manufacturing problems and the absence of comparable information on heat transfer and pressure loss [20]. Thus, to investigate the heat transfer characteristics of STHXs with disk-and-doughnut baffles becomes our main purpose in this research.

\section{Experimental Apparatus and Method}

A schematic diagram of the experimental apparatus process is shown in Figure 1. It is mainly composed of the experimental model with two closed-loop systems. The left loop of the experimental model is heating circularly system, which is keeping the inlet of passing flow with shell side at constant temperature of $60^{\circ} \mathrm{C}$, and the right loop of the experimental model is cooling circularly system, which is also keeping the inlet of passing flow with tube side at constant temperature of $10^{\circ} \mathrm{C}$. The cooling and heating flow are arranged counter flow through the vertical arrangement model. The core part arranged between two circularly system is the targeting experimental model, which has been installed disk-and-doughnut baffles with thermocouple temperature sensors as shown as Figure 2. Every 2 pieces thermocouples (T type, "W" models, measurement range in the $200^{\circ} \mathrm{C}$ to $350^{\circ} \mathrm{C}$ ) are inserted into the flow at inlet and outlet of the shell-side and tube-side respectively for measuring the bulk temperature of the counter passing flow. Additionally, 10 other same type thermocouples (No.0 - No.9) are equidistantly welded on the surface of copper tube respectively along the whole test length for validating the wall temperature variation and measuring average wall temperature. The data acquisition system (data logger, Yokogawa DA 100 with $\pm 0.1^{\circ} \mathrm{C}$ accuracy, 10 to 40 channels input and $200^{\circ} \mathrm{C}$ to $1100^{\circ} \mathrm{C}$ measurement temperature range) has a precision of $0.1^{\circ} \mathrm{C}$ and all the thermocouples are calibrated before being attached to the testing section. The detailed dimension of the model is shown in Table 1.

The typical experiments model is designed under guidance of the numerical simulation (via CFD program) conducted in advance for verifying the numerical 


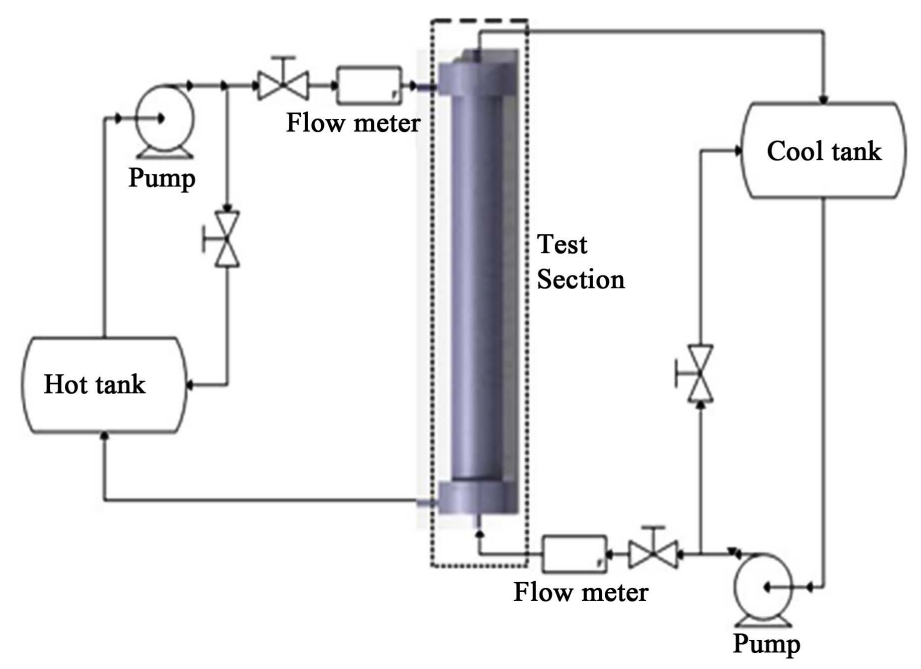

Figure 1. A schematic diagram of the experimental setup process.

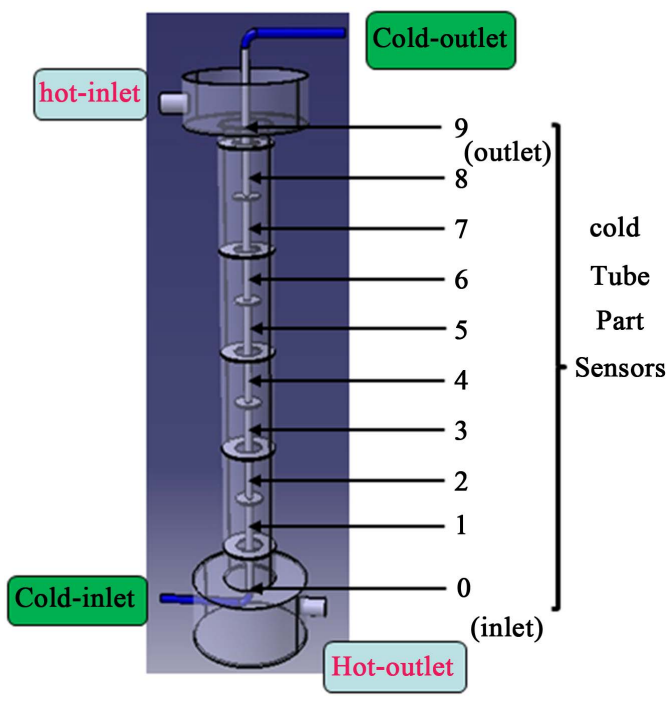

Figure 2. The diagram of experimental model.

Table 1. The detail dimensions of the model.

\begin{tabular}{|c|c|c|c|c|c|c|c|c|c|}
\hline & \multicolumn{5}{|c|}{ Copper tube } & \multicolumn{4}{|c|}{ shell } \\
\hline material & \multicolumn{5}{|c|}{$\mathrm{C} 1220 \mathrm{~T}$} & \multicolumn{4}{|c|}{ plastic } \\
\hline $\mathrm{Do} / \mathrm{Di}(\mathrm{mm})$ & \multicolumn{5}{|c|}{$12.7 / 11.1$} & \multicolumn{4}{|c|}{$100 / 94$} \\
\hline Length (mm) & \multicolumn{4}{|c|}{720} & & \multicolumn{4}{|c|}{720} \\
\hline Length of baffles section (mm) & \multicolumn{9}{|c|}{440} \\
\hline \multicolumn{10}{|c|}{ The parameters of baffle } \\
\hline material & & & & & plastic & & & & \\
\hline numbers & & 5 & & & 7 & & & 9 & \\
\hline BCR (\%) & 60 & 70 & 80 & 60 & 70 & 80 & 60 & 70 & 80 \\
\hline Spacing $(\mathrm{mm})$ & & 110 & & & 73.3 & & & 55 & \\
\hline Thickness (mm) & & & & & 3 & & & & \\
\hline
\end{tabular}


prediction. The numerical result simulated by varying the parameters of the baffles numbers, baffle cutting ratio and mass flow rate respectively, which is illustrated as shown from Figures 4-7. The subsequent experiments are conducted after numerical simulation for further discussion of the characteristics of heat transfer performance of STHXs with disk and doughnut baffles. The experimental results are illustrated also as shown in Figures $8-11$. The baffle cutting ratio is defined in Figure 3.

The heat calculations are referred as the following correlations:

Heat exchange rate of shell-side fluid:

$$
\Phi_{s}=M_{s} \times c_{p t} \times\left(t_{s, \text { out }}-t_{s, \text { in }}\right)
$$

Heat exchange rate of tube-side fluid:

$$
\Phi_{t}=M_{t} \times c_{p t} \times\left(t_{t, \text { out }}-t_{t, \text { in }}\right)
$$

Due to unavoidable heat loss of testing section in practice, for calculation accuracy, the average heat exchange rate is defined as

$$
\Phi_{\text {average }}=\frac{\Phi_{s}+\Phi_{t}}{2}
$$

Overall heat transfer coefficient $k$ is equal to:

$$
\begin{gathered}
k=\frac{\Phi_{\text {ave }}}{A_{o} \cdot \Delta t_{m}} \\
A_{o}=N_{t} \cdot \pi d_{o} l \\
\Delta t_{m}=\frac{\Delta t_{\max }-\Delta t_{\min }}{\ln \left(\Delta t_{\max } / \Delta t_{\min }\right)} \\
\Delta t_{\max }=t_{s, \text { in }}-t_{t, \text { out }} \\
\Delta t_{\min }=t_{s, \text { out }}-t_{t, \text { in }}
\end{gathered}
$$

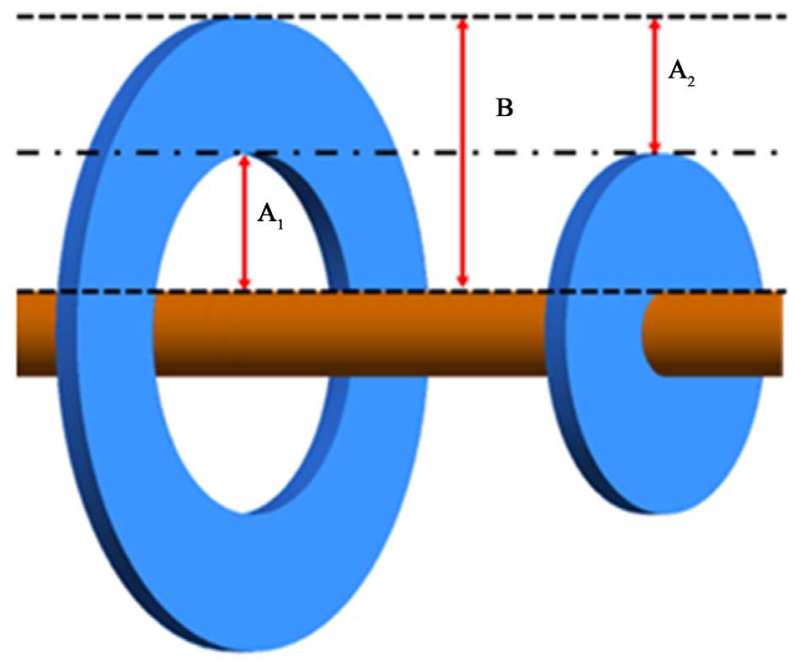

Baffle cutting ratio: $\mathrm{BCR}=\mathrm{A} 1 / \mathrm{B}=1-\mathrm{A} 2 / \mathrm{B}$

Figure 3. The diagram of baffle cutting ratio. 


\section{Result and Discussion}

\subsection{Numerical Simulation Prediction}

The computational fluid dynamic commercial code ANSYS Fluent 12 is employed to solve the present simulation. This set of nonlinear differential equations was solved by finite volume method. Finite volume method converts the governing equations to a set of algebraic equations that can be solved numerically. The algebraic "discretize equations" resulting from spatial integration process, sequentially solved throughout the physical domain considered. ANSYS Fluent 12 solves the systems resulting from discretization schemes using a numerical method. For the convective and diffusive terms, a second order upwind method was used. Pressure and velocity were coupled using Semi Implicit Method for Pressure Linked Equations (SIMPLE). The converged solution was keep maintained to achieve with very low level of these residual about $10^{-6}$.

The experiment contents were simulated in advance via ANSYS Fluent 12 program by setting the initial conditions (Tap water flow, Tube-side inlet flow rate $\mathrm{LPM}=4$, Inlet flow temperature $10^{\circ} \mathrm{C}$, wall material: copper as etc.) in order to guide the experimental process. The numerical result is showed as Figures 4-7.

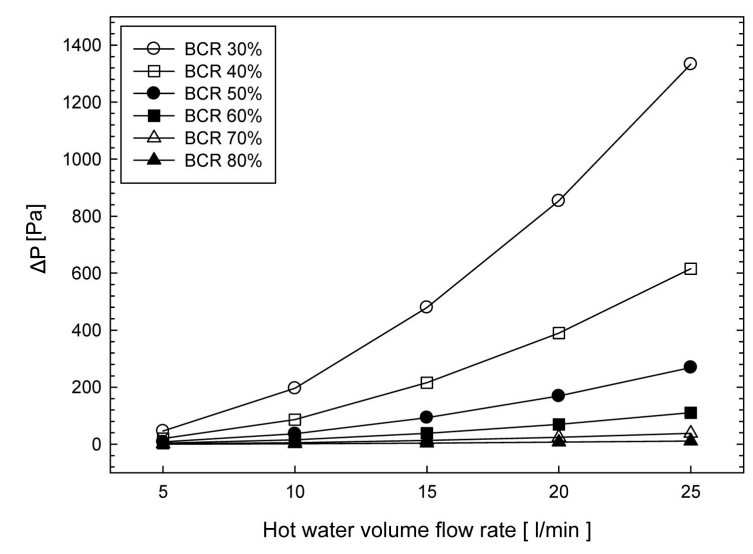

Figure 4. Baffle number.

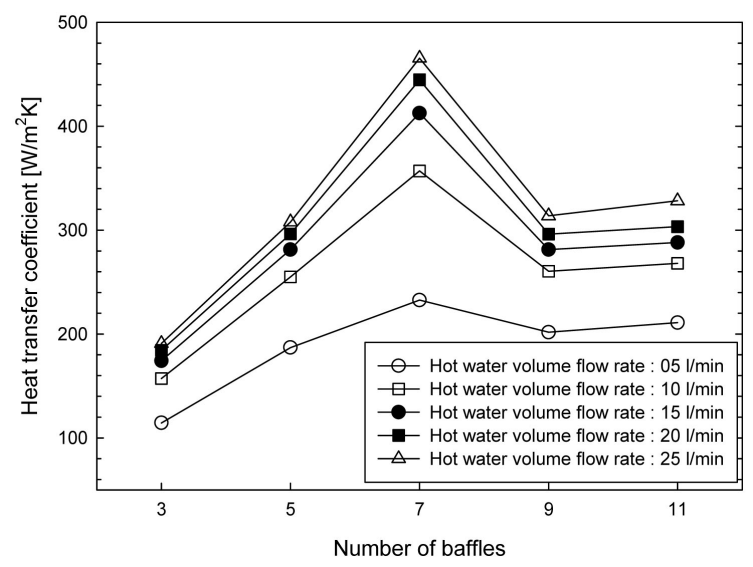

Figure 5. Baffle number. 


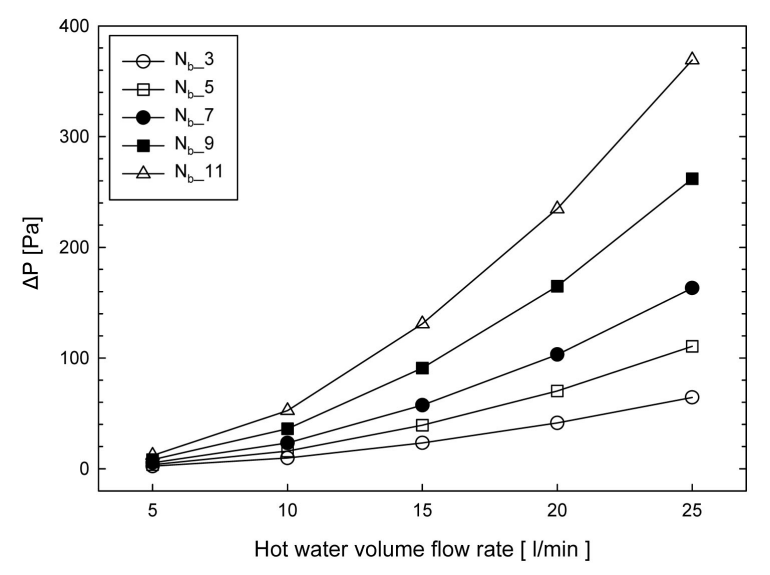

Figure 6. BCR. The best performance at BCR 70\%.

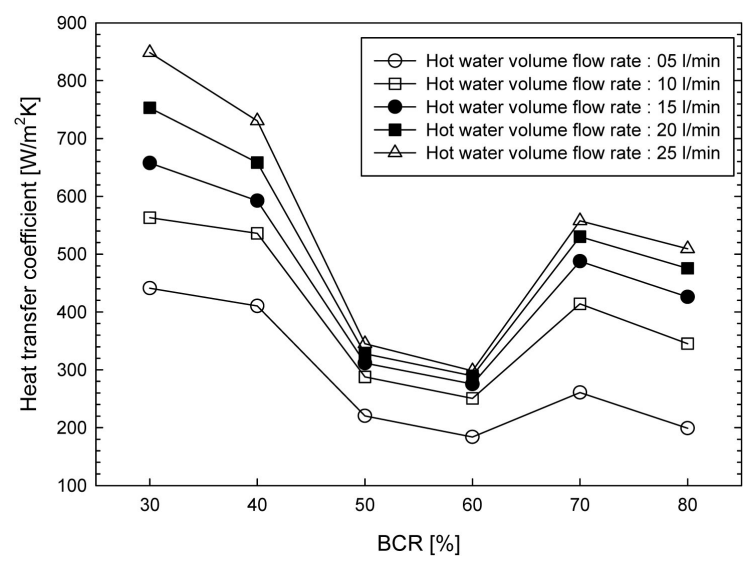

Figure 7. BCR. The best performance at BCR 70\%.

As known that the criteria of best design for any STHXs should be getting optimal heat transfer coefficient with lowest pressure drop penalty, because the pressure drop causes the increase of the operating cost of fluid moving device such as pump and fun. Obviously, Figure 4 illustrates that the pressure drop is decreased with increasing the BCR and it is increased with increasing the shell side (hot water) mass flow rate. The heat transfer coefficient gets the maximum at 7 baffle configuration as varying shell side mass flow rate as shown in Figure 5 , the pressure drop increased as increasing the baffle quantity as shown in Figure 6. Figure 7, respectively, which illustrates that the heat transfer coefficient is decreased as increasing the $\mathrm{BCR}$, however the tendency is contrary remarkably at $70 \% \mathrm{BCR}$ configuration. In comprehensive consideration about approaching the balance between the thermal design and pressure drop, the numerical simulation datum shown that the STHXs at 7 baffles (from Figure 4 and Figure 5) with $70 \%$ BCR (from Figure 6 and Figure 7) is the best design according to the STHXs criteria. From foregoing the prediction of numerical simulation results, the experiments were conducted as well at 9 baffles and BCR at 50\% configuration as typical model in order to further validate the heat transfer characteristics of this type STHXs, which is discussed in Table 1. 


\subsection{Experimental Results for Heat Transfer Performance}

The typical experimental model is designed at 9 baffles and 50\% BCR, the heat transfer calculation base on above the basic correlations (1), (2), (3), (4), the flow rate unit " $1 / \mathrm{min}$ " is written as "LPM". The experimental result is showed in Figure 8 and Figure 9.

From Figure 8 and Figure 9 we can get that the tendency of average heat transfer rate $\mathrm{Q}$ and overall heat transfer coefficient $\mathrm{k}$ both increase as increasing the tube part mass flow rate, especially both of $\mathrm{Q}$ and $\mathrm{k}$ increase considerably when the mass flow rate reached to the turbulent flow regime (especially when Tube part flow Re $>4000$ ). Furthermore, from Figure 8 and Figure 9 can be shown that to increase the mass flow rate of cold part is much more significant on increasing the $\mathrm{Q}$ and $\mathrm{k}$ than that of hot part in the turbulent regime (about $4000<\operatorname{Re}<11,000$ ), thus to vary the mass flow rate of tube side is the efficient way to influence the heat transfer coefficient in the STHXs, especially in the turbulent flow regime.

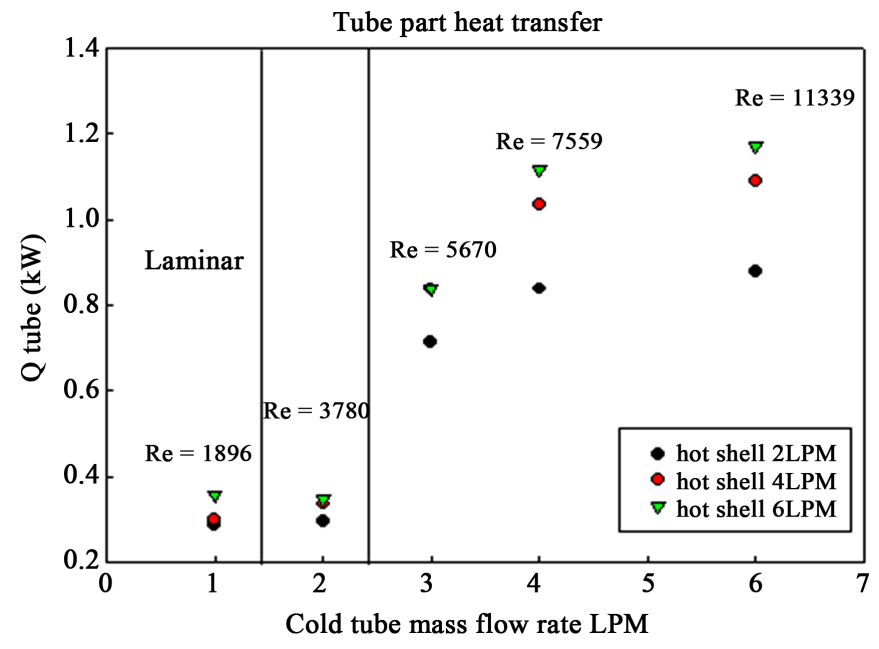

Figure 8. Q base on tube-side mass flow rate.

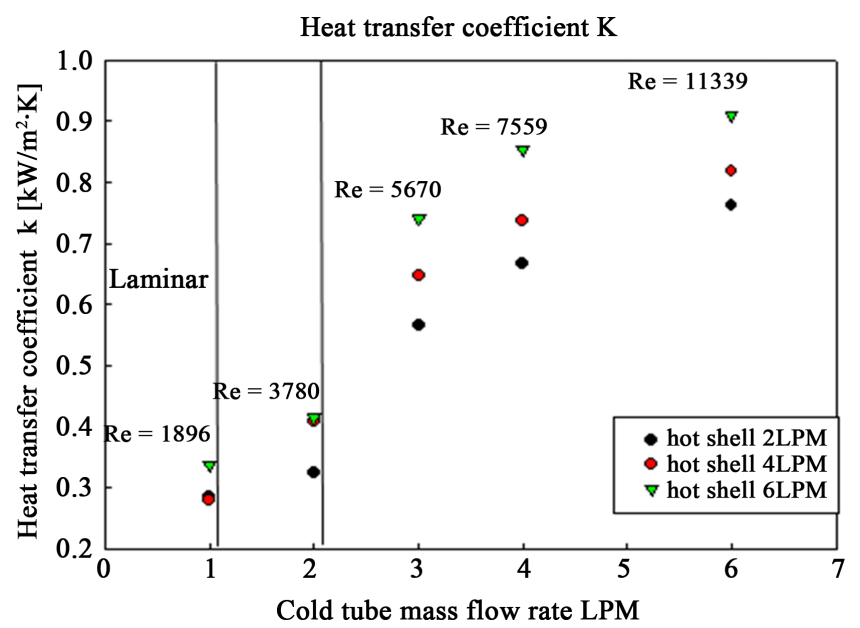

Figure 9. K base on tube-side mass flow rate. 


\subsection{Experimental Results for Temperature Distribution}

As shown the experimental model in Figure 10, Figure 11. It is exhibited that the temperature distribution along the tube-side when the cooling flow passing through at different flow rate, respectively.

Figure 10 illustrates that the temperature distribution curves decline remarkable as increasing the cold tube mass flow rate when the hot shell side mass flow rate keeps constant in turbulent flow regime (hot shell side $2 \mathrm{PM}>\operatorname{Re} 3780$ ). In contrast, Figure 11 shows that the temperature distribution curves are insensitive by variation of the hot shell side mass flow rate when cold tube mass flow rate keeps constant in the turbulent flow regime (cold tube side $3 P M=\operatorname{Re} 5670$ ).

From the correlation (4) calculated, the temperature distribution results exhibited in Figure 10 and Figure 11, it further demonstrates that increasing the mass flow rate of tube side is much more effective on heat transfer coefficient in this type of STHXs than that of shell side in the turbulent flow regime.

The temperature distribution along tube-side at hot shell-side 2LPM

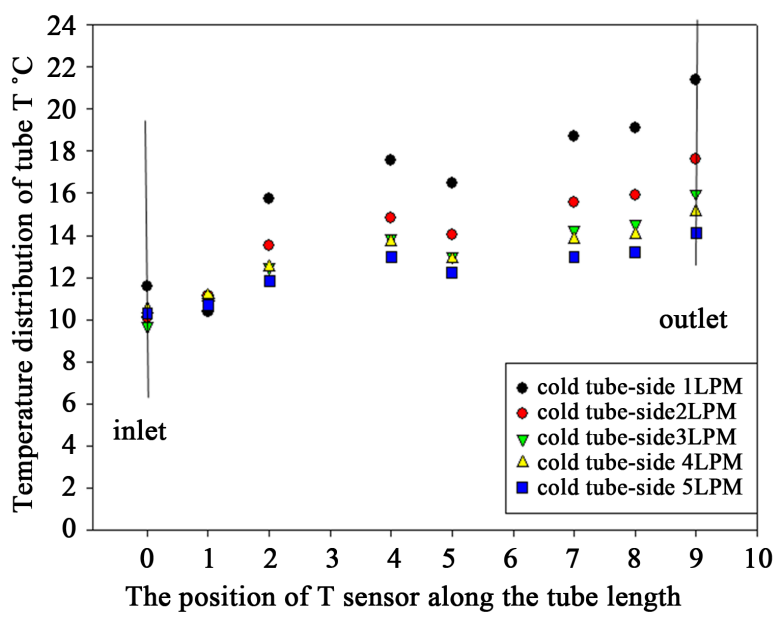

Figure 10. The temperature distribution along tube-side at hot shell-side 2LPM.

The temperature distribution along tube-side at cold tube-side 3LPM

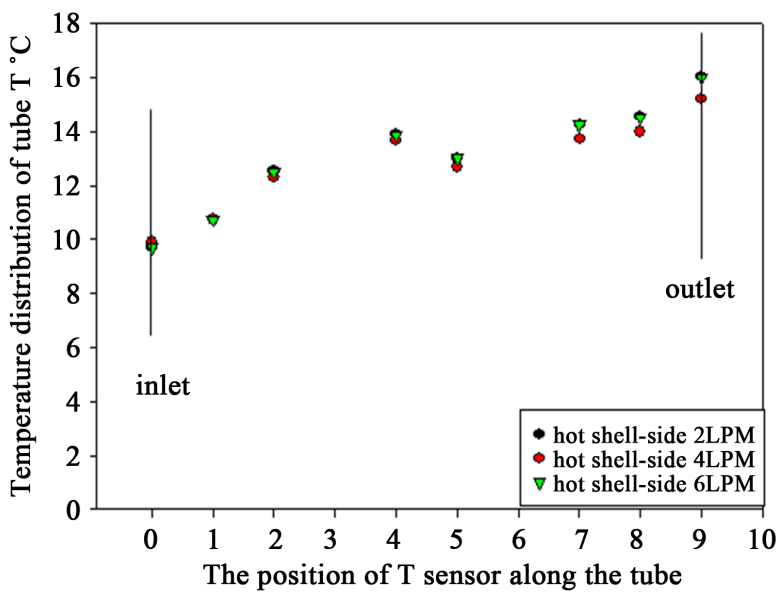

Figure 11. The temperature distribution along tube-side at cold tube-side 3LPM. 


\section{Conclusions}

From numerical simulation by CFD program, it suggested that STHXs with disk and doughnut baffles model at the configuration of 7 baffles, and 70\% BCR have the best performance.

From the experimental investigation, the heat transfer coefficient is insignificant as varying the mass flow rate of both sides in the laminar flow regime. In contrast, varying the mass flow rate of both sides induces higher effectiveness on the heat transfer coefficient in turbulent flow regime. Furthermore, increasing the mass flow rate of tube side is much more effective on heat transfer coefficient in this type of STHXs than that of shell side in the turbulent flow regime. Therefore, trying to increase the tube side flow velocity to improve heat transfer enhancement of this type of STHXs is one of the efficient ways suggested in the actual design work.

The further investigation is allowed to improve the best deign configuration and heat transfer performance for the STHXs with disk and doughnut baffles in the future.

\section{Conflicts of Interest}

The authors declare no conflicts of interest regarding the publication of this paper.

\section{References}

[1] Li, H. and Kottke, V. (1999) Analysis of Local Shellside Heat and Mass Transfer in the Shell-and-Tube Heat Exchanger with Disc-and-Doughnut Baffles. International Journal of Heat \& Mass Transfer, 42, 3509-3521. https://doi.org/10.1016/S0017-9310(98)00368-8

[2] Wang, W.-H., Cheng, D.-L., Liu, T. and Liu, Y.-H. (2016) Performance Comparison for Oil-Water Heat Transfer of Circumferential Overlap Trisection Helical Baffle Heat Exchanger. Journal of Central South University, 23, 2720-2727. https://doi.org/10.1007/s11771-016-3333-4

[3] Master, B.I., Chunangad, K.S. and Pushpanathan, V. (2003) Fouling Mitigation Using Helixchanger Heat Exchangers. Proceedings of the ECI Conference on Heat Exchanger Fouling and Cleaning. Fundamentals and Applications, Santa Fe, 18-22 May 2003, 317-322.

[4] Bell, K.J. (1986) Delaware Method of Shell Side Design. In: Heat Exchanger Sourcebook, Hemisphere Publisher, New York, 129-166.

[5] Bell, K.J. (1988) Delaware Method of Shell-Side Design. In: Heat Transfer Equipment Design, Hemisphere Publishing Corp., New York, 7, 86.

[6] Bell, K.J. (2004) Heat Exchanger Design for the Process Industries. Journal of Heat Transfer, 126, 877-885. https://doi.org/10.1115/1.1833366

[7] Zhang, J.F., Li, B., Huang, W.J., et al. (2009) Experimental Performance Comparison of Shell-Side Heat Transfer for Shell-and-Tube Heat Exchangers with Middle-Overlapped Helical Baffles and Segmental Baffles. Chemical Engineering Science, 64, 1643-1653. https://doi.org/10.1016/j.ces.2008.12.018

[8] Li, H.D. and Kottke, V. (1997) The Effect of Baffle-Tube Leakage on the Local Mass 
and Heat Transfer in the Shell Side of Shell-and-Tube Heat Exchangers. Journal of Flow Visualization \& Image Processing, 4, 129-139. https://doi.org/10.1615/JFlowVisImageProc.v4.i2.40

[9] Li, H.D. and Kottke, V. (1998) Effect of the Leakage on Pressure Drop and Local Heat Transfer in Shell-and-Tube Heat Exchangers for Staggered Tube Arrangement. International Journal of Heat and Mass Transfer, 41, 425-433. https://doi.org/10.1016/S0017-9310(97)00112-9

[10] Li, H.D. and Kottke, V. (1998) Effect of Baffle Spacing on Pressure Drop and Local Heat Transfer in Shell-and-Tube Heat Exchangers for Staggered Tube Arrangement. International Journal of Heat \& Mass Transfer, 41, 1303-1311. https://doi.org/10.1016/S0017-9310(97)00201-9

[11] Sharif, A., Klein, D. and Howell, J.R. (1991) Effectiveness of Pressure Drop to Heat Transfer Conversion for Various Shellside Flow Configurations. ASME/JSME Thermal Engineering Proceedings, 4, 439-448.

[12] Sparrow, E.M. and Perez, J.A. (1985) Internal, Shellside Heat Transfer and Pressure Drop Characteristics for a Shell and Tube Heat Exchanger. Journal of Heat Transfer, 107, 345. https://doi.org/10.1115/1.3247421

[13] Weaver, D.S. and Fitzpatrick, J.A. (1988) A Review of Cross-Flow Induced Vibrations in Heat Exchanger Tube Arrays. Journal of Fluids and Structures, 2, 73-93. https://doi.org/10.1016/S0889-9746(88)90137-5

[14] Mukherjee, R. (1992) Use Double-Segmental Baffles in the Shell-and-Tube Heat Exchangers. Chemical Engineering Progress, 88, 47-52.

[15] Saffar-Avval, M. and Damangir, E. (1995) A General Correlation for Determining Optimum Baffle Spacing for All Types of Shell and Tube Exchangers. International Journal of Heat and Mass Transfer, 38, 2501-2506. https://doi.org/10.1016/0017-9310(94)00358-3

[16] Stehlik, P. and Wadekar, V.V. (2002) Different Strategies to Improve Industrial Heat Exchange. Heat Transfer Engineering, 23, 36-48. https://doi.org/10.1080/01457630290098673

[17] Soltan, B.K., Saffar-Avval, M. and Damangir, E. (2004) Minimizing Capital and Operating Costs of Shell and Tube Condensers Using Optimum Baffle Spacing. Applied Thermal Engineering, 24, 2801-2810. https://doi.org/10.1016/j.applthermaleng.2004.04.005

[18] Ratnasamy, F. (1987) Exchanger Design Using Disc-and-Dough-Nut Baffles. Hydrocarbon Process, 66, 63-65.

[19] Hu, X. and Jacobi, A.M. (1996) The Intertube Falling Film: Part 1 Flow Characteristics, Mode Transitions, and Hysteresis. Journal of Heat Transfer, 118, 616-625. https://doi.org/10.1115/1.2822676

[20] Taborek, J. (1991) Selected Problems in Heat Exchanger Design. Proceedings of the EUROTHERM Seminar, No. 18, Hamburg, 3-18.

https://doi.org/10.1007/978-3-642-84450-8_1 